- Constantopoulos, A. A., Jardine, M. Y. \& McGuffin, P (1978) A clinical scale for the self-assessment of irritability. British Journal of Psychiatry, 132, 164-171.

\section{Self-Poisoning and Suicide Attempts by Burning}

SIR: The use of the term suicide 'epidemic' is fashionable. Both Farmer (Journal, May 1987, 150, 609614) and Zemishlany et al (Journal, May 1987, 150, 704-706) use the term, in the former article to describe incidence trends in the general population, and in the latter to focus on the timing of three suicide attempts in a psychiatric hospital.

One should ask whether the 'epidemic model' of suicide is the appropriate concept for the phenomena being described. Strictly speaking, such a model would require the criteria of an epidemic, such as the identification of a 'host', a 'vector', and a 'mode of transmission' of a 'noxious agent', to be fulfilled.

Currently, there appears to be a resurgence of research interest in the 'Werther effect', referring to the phenomenon where newspaper publicity of suicides is apparently associated with an increase in suicide rates (Phillips, 1974). Phillips coined this term 200 years after Goethe's romantic novel The Sorrows of the Young Werther was banned in a number of centres in Europe for allegedly providing a model for imitative suicides. Some caution needs to be exercised in the labelling of increased suicide rates or of suicide clusters as "epidemics". Implied in the designation of a suicide "epidemic" based on imitation are preventative measures (such as the literary censorship that befell Goethe's novel), one being the suggestion that "educators, policy makers, and journalists may wish to consider ways of reducing public exposure to stories, both general and specific, about suicide (Phillips \& Carstensen, 1986). While this recommendation may have superficial appeal, and may eventually be based on experimental evidence, the imitative propagation hypothesis to explain national suicide rate increases still awaits replicable proof.

Turning to suicide clusters, suggestible individuals, whether 'normal' young people or vulnerable adults in institutional settings such as hospitals or prisons, are more likely to be influenced by the basic psychological process of identification than by suggestion or imitation (Halasz, 1987) and the recommendation of "group sessions after a suicidal case in order to neutralise the identification with the act by suggestible patients" (Zemishlany et al) seems a clinical imperative.

However, this is a clinical recommendation, not in need of an epidemic model of explanation. Rather, it underlines the need for clinicians to recognise individual vulnerability in normal developmental phases, as occurs in childhood and adolescence, as well as in stress-induced regressed adult states brought about by illness, or dramatic changes in personal degrees of freedom.

George Halasz

Austin Hospital

Heidelberg

Victoria 3084

Australia

\section{References}

HaLASZ, G. (1987) Imitation, suggestion, identification - possible psychological factors in suicidal behaviour. Presented at the 23rd Annual Congress, The Royal Australian and New Zealand College of Psychiatrists, Auckland, New Zealand, 10-15 May.

PHILLIPS, D. P. (1974) The influence of suggestion on suicide: substantive and theoretical implications of the Werther effect. American Sociological Review, 39, 340-354.

Phillus, D. P. \& Carstensen, M. S. (1986) Clustering of teenage suicides after television news stories about suicide. New England Journal of Medicine, 315, 685-689.

\section{No Fixed Abode}

SIR: We read with interest the recent report by Herzberg (Journal, May 1987, 150, 621-627). We compared four groups of patients: urban fixed abode, urban 'no fixed abode' (NFA), and rural and semi-rural consecutive male psychiatric admissions, with 50 patients in each cell (O'Shea et al, 1983). This study also used retrospective case-note information.

Poor employment records and early parental separation were common in the NFA group; rural men generally live with others, the homeless tend to be single (NFA: married, 3; single, 40; separated, 6; divorced, 1; widowed, 0 ); age did not differentiate any of the groups; all groups shared "chronic schizophrenia' and 'alcoholism' as the chief diagnostic categories; the strong impression was gained that alcohol-related difficulties were generally underestimated; patients in the NFA group were more likely to have legal records; standard diagnostic methods were hardly ever employed; physical pathology was common and widespread in all four groups; routine ancillary tests were not readily available; and most patients came from the lower socioeconomic levels of society.

Specifically, the physical findings among the NFA group were: eight men had chronic obstructive airways disease, mostly with acute exacerbations at the time of admission; three, one with a past history of cerebrovascular accident, were hypertensive, and all of these were on hypotensive drugs; the man with the stroke had a residual hemiparesis and epilepsy; two other cases had experienced alcohol-related convulsions; a fourth man's fits were found to be due to an 
inoperable glioma; one alcoholic was unable to walk because of peripheral neuropathy; one hypertensive patient had angina pectoris, another was diabetic, and a third required surgery for varicose leg veins; six men had anaemia of nutritional origin-one had undergone sub-total gastrectomy 30 years previously; one young patient had a marked strabismus; three men had had duodenal ulcers, two having received surgery for this; two had a history of hepatitis; and five had received anti-tuberculosis chemotherapy within five years of admission. Ten of the NFA patients were grossly obese.

The finding of a high physical morbidity among both urban groups is in keeping with other reported work (Feldman et al, 1974). The fact that all four groups shared this unenviable record is most likely related to the fact that they had psychiatric illnesses (Cutting, 1980; Sims, 1978; Sims \& Prior, 1978).

BRIAN O'ShEA

Newcastle Hospital MARTIN RAHILL

Greystones

Co. Wicklow

St Brendan's Hospital

Rathdown Road

Dublin 7

\section{References}

Curring, J. (1980) Physical illness and psychosis. British Journal of Psychiatry, 136, 109-119.

Feldman, J., Kaley, M. M. \& Kissin, B. (1974) Skid row and inner city alcoholics. Quarterly Journal of Studies in Alcohol, 35, 565-574.

O'Shea, B., Falvey, J., Bereen, F. J. \& Egan, T. (1983) Relationship between abode and morbidity. Psychiatric Nursing, 2, 27-33.

Sims. A. (1978) Hypotheses linking neuroses with premature mortality. Psychological Medicine, 8, 255-263.

- \& PRIOR, P. (1978) The pattern of mortality in severe neuroses. British Journal of Psychiatry, 133, 299-305.

\section{Late Paraphrenia or the Paraphrenias}

SIR: Holden (Journal, May 1987, 150, 635-639) perpetuates the confusion surrounding paranoid states in the elderly. A major contribution to this has to be the continuing reluctance to diagnose schizophrenia arising for the first time in patients over the arbitrary age of 40 or 45 .

Holden appears to be using the term "late paraphrenia' in a very broad sense, including within the definition all cases of paranoia arising de novo after the 60 th birthday. This is not in keeping with the clear definition of Kay \& Roth (1961) he quotes.

I suspect that the 'organic' group could have been identified at the time of the initial contact, and it may be that the Gresham Ward Questionnaire is not sensitive enough to identify clinically important levels of poor cognitive function. It is interesting to note that the 'organic' group comprised $35 \%$ of the final sample, a figure not dissimilar to Post's "up to $30 \%$ ". Paranoid symptoms are well known in patients suffering from organic brain syndromes (Ballinger et al, 1982) and the poor prognosis for organic brain syndromes has been known for some years (Roth, 1955; Christie, 1982; Blessed \& Wilson, 1982).

I cannot agree with Holden that the differences between the concepts of "late paraphrenia" (Kay \& Roth, 1961) and "persistent persecutory states of the elderly" (Post, 1966) have not been clearly resolved. The title of the Kay \& Roth (1961) paper should leave one in no doubt as to their view of late paraphrenia. My own review of the term (Grahame, 1982) concluded that late paraphrenia is one of the schizophrenias, and this was supported by a later clinical study (Grahame, 1984).

Holden's final paragraph is, for me, the most confusing and $I$ cannot see how the data presented support such a conclusion. Organicity is important in the genesis of 'persistent persecutory states of the elderly' but not of 'late paraphrenia', which in my view is as homogenous a clinical syndrome as any known to psychiatry. After all, there is no dispute about schizophreniform psychosis secondary to, say, trauma in young patients and the functional schizophrenias. The fact that some patients with late paraphrenia subsequently develop an organic brain syndrome should not necessarily lead one to say that the late paraphrenia was a symptom of an organic brain syndrome. Just over $40 \%$ of patients in the Blessed \& Christie (1982) study had an organic brain syndrome, and they comment that their findings "again lend little support to the idea that functional illness in old age is the harbinger of senile or arteriosclerotic psychosis". Inspection of Table I of Blessed $\&$ Wilson (1982) shows what they consider late paraphrenia to be.

Finally, had Holden interviewed his patients using the Geriatric Mental Status Interview, he may well have found more patients reporting first rank symptoms which, in turn, may have had a significant effect on his final groupings.

Severalls Hospital

P.S. GRAHAME

\section{Boxted Road}

Colchester, Essex CO4 $5 H G$

\section{References}

Ballunger, B. R., Reto, A. H. \& Heather, B. B. (1982) Cluster analysis of symptoms in elderly demented patients. British Journal of Psychiatry. 140, 257-262. 